regular basis, and half of these wished for more contact. Thirty-three per cent were seeing their GP monthly or more but most were less than twice a year. The need for an improved system of reviewing medication has been recommended and a local service proposed. Ways of educating more proprietors and residents on the purpose and effects of medication are being investigated. The most common request was for an increase in service from social workers; only one in five had any contact. This highlights the importance of non-medical problems in this group. Community psychiatric nurses were seen by only $14 \%$ and few wanted increased contact. Other services that were used included dentist $(4 \%)$, optician ( $1 \%)$, chiropodist $(6 \%)$. In view of the ageing nature of these people, the level of contact seems very low. Encouragement to have regular check-ups would be worthwhile to maintain a good level of health.

What are the conclusions and the results of this work? For many people a boarding house is equivalent to a staffed hostel, and is what they need. More selective matching of people's skills to particular houses and finding ways to increase or maintain their independence were suggested. Proprietors have had to handle difficult situations, often with very little support. The need for better organised and closer support for the boarding houses is proposed. Already link social workers and a community psychiatric nurse with special responsibility for this client group have been established. The beginnings of a specialist team are being funded over the next few years. Information and training opportunities are being started for proprietors and the first course, currently running, appears to be going well.
The need for day-care facilities-occupational, leisure and social-were highlighted and two jointly financed project development posts are being advertised. They will develop, with the other agencies, the variety of work and leisure schemes required. One very real benefit from the survey has been the improved understanding and communication between statutory, voluntary and private sectors.

An unexpected aspect of the project has been the number of presentations of the results we have done for different groups, and the amount of interest shown. As one proprietor said, "We were rather sceptical about the research in the beginning, we have had promises before, but this time we're impressed." This is an exciting period for developing services in our area. We want to show that care in the community' means just that for people in our district.

\section{ACKNOWLEDGEMENTS}

We would like to thank the following for their help: $\mathrm{Mr} \mathrm{P}$. Hill, Ms P. Weston (Research Assistants), the local health and social service personnel, Mental Aftercare Association, proprietors and residents who took part.

\section{REFERENCE}

'HALL, J. \& BAKER, R. (1983) Rehabilitation Evaluation. Aberdeen: Vine.

This is the third of a series of four papers to be published in the Bulletin on rehabilitation developments at Severalls Hospital.

\title{
The European Association of Geriatric Psychiatry
}

The European Association of Geriatric Psychiatry (EAG) was founded on 1 October 1987 and is the successor of the unregistered European Association of Geriatric Psychiatry founded in 1971. Its aim is to advance research, practice and education in the field of geriatric psychiatry and to cooperate with persons, national and international bodies whenever these further the purposes of the EAG. The EAG organises regular conferences and workshops and its 16th symposium will take place on 7 and 8 October 1988 in Amsterdam. The annual subscription will be DM 50 . Persons with a recognised professional qualification in research, practice and education in the field of geriatric psychiatry can become full members; the application must be supported by two members. Supporting members are welcome.

Application forms can be ordered from the secretariat or from any of the executive board members.

\author{
Chairman: Dr Chr. Kretschmar \\ Rheinische Landesklinik, Psychiatrische \\ Klinik der Universität, D-4000 Düsseldorf 12 \\ Bergische Landstrasse 2, Germany. \\ 1st Vice-chairman: Professor R. Levy \\ Institute of Psychiatry, De Crespigny Park \\ Denmark Hill, London SE5 8AF. \\ 2nd Vice-chairman: Dr J. U. Postma \\ NL-1181 XJ Amstelveen, Mr Aalberselaan 13 \\ The Netherlands. \\ Secretary: Primaria Dr M. E. Kalousek \\ Psychosoziale Station \\ A-1020 Wien, Kleine Sperlgasse 2b \\ Austria. \\ Treasurer: Dr J. H. Kretschmar \\ D-4020 Mettmann, Kantstrasse 3 \\ Germany.
}

